\title{
Generation of Human Pulmonary Microvascular Endothelial Cell Lines
}

\author{
Vera Krump-Konvalinkova, Fernando Bittinger, Ronald E. Unger, Kirsten Peters, \\ Hans-Anton Lehr, and C. James Kirkpatrick \\ Institute of Pathology, Johannes-Gutenberg University, Mainz, Germany
}

\begin{abstract}
SUMMARY: The limited lifespan of human microvascular endothelial cells in cell culture represents a major obstacle for the study of microvascular pathobiology. To date, no endothelial cell line is available that demonstrates all of the fundamental characteristics of microvascular endothelial cells. We have generated endothelial cell lines from human pulmonary microvascular endothelial cells (HPMEC) isolated from adult donors. HPMEC were cotransfected with a plasmid encoding the catalytic component of telomerase (hTERT) and a plasmid encoding the simian virus 40 (SV40) large T antigen. Cells transfected with either plasmid alone had an extended lifespan, but the cultures eventually entered crisis after several months of proliferation. Only those cells that were transfected with both plasmids acquired the capacity to grow in vitro without demonstrating major crisis, and these cells have been in culture for 24 months. HPMEC isolated from two different donors were used, generating two populations of immortalized cells, HPMEC-ST1 and HPMEC-ST2. Single cell-derived clones of the immortalized cells HPMEC-ST1 exhibited growth characteristics that were similar to those of the parental HPMEC. One selected clone, HPMEC-ST1.6R, displayed all major constitutively expressed and inducible endothelial phenotypic markers, including platelet endothelial cell adhesion molecule (PECAM-1, CD31), von Willebrand factor (vWF), and the adhesion molecules, intercellular adhesion molecule (ICAM-1), vascular adhesion molecule (VCAM-1), and E-selectin. In addition, an angiogenic response was demonstrated by sprout formation on a biological extracellular matrix (Matrigel). The HPMEC-ST1.6R cells did not form tumors in nude mice. The microvascular endothelial cell line, HPMEC-ST1.6R, will be a valuable tool for the study of microvascular endothelial physiology and pathology including gene expression, angiogenesis, and tumorigenesis. (Lab Invest 2001, 81:1717-1727).
\end{abstract}

$V$ ascular endothelial cells mediate the interactions between blood and tissue and play an essential role in angiogenesis, the regulation of blood flow, vascular permeability, wound healing, inflammation, atherosclerosis, and metastasis (Cines et al, 1998). Most of our knowledge of human endothelial cell function is derived from experiments with cultured human umbilical cord vein endothelial cells (HUVEC). Several permanent endothelial cell lines have been extensively used (Ades et al, 1992; Edgell et al, 1983; Takahashi et al, 1990), but none show all of the fundamental characteristics of endothelial cells, such as the constitutive expression of platelet endothelial cell adhesion molecule (PECAM-1, CD31) and von Willebrand factor (vWF), the ability to up-regulate the production of cell adhesion molecules upon exposure to proinflammatory stimuli, and an angiogenic response. Some have been shown to be of questionable endothelial origin (Drexler, 1999). Neither HUVEC that are of macrovascular embryonic origin nor the currently available permanent cells lines are representative for adult microvascular endothelium. Relevant cell culture models are crucial to the study of the pathobiology of the lung microvascular endothelium and an understanding of lung metastasis (Lehr et al, 2000)

Received September 24, 2001.

Address reprint requests to: Dr. C. J. Kirkpatrick, Institute of Pathology, Johannes-Gutenberg University, Langenbeckstrasse 1, D-55101 Mainz, Germany.E-mail: kirkpatrick@pathologie.klinik.uni-mainz.de and disorders such as acute respiratory distress syndrome (Kirkpatrick et al, 1996).

One of the principal obstacles to setting up experiments with primary isolated human pulmonary microvascular endothelial cells (HPMEC) is the limited lifespan of normal human diploid cells in culture. The proportion of actively dividing cells typically decreases after a finite number of divisions, and the population enters a state of growth arrest or replicative senescence. According to a widely accepted hypothesis, the cells stop dividing after telomeric repeat sequences, which shorten at each replication, have reached a minimum length (Olovnikov, 1973). Ectopic expression of the catalytic component of telomerase (hTERT) can compensate for the consequences of telomere shortening and extend the lifespan of cultured cells beyond senescence. However, reports are controversial with respect to the necessity for additional genetic events required for the immortalization of various cell types. Although an expression of telomerase is sufficient for the immortalization of human fibroblasts, retinal pigment epithelial cells, and an extension of the lifespan of neonatal endothelial cells (Bodnar et al, 1998; Jiang et al, 1999; Yang et al, 1999), the immortalization of human foreskin keratinocytes and epithelial cells requires additional genetic events. Abrogation of the cyclin dependent kinase inhibitor $\mathrm{pRB} / \mathrm{p} 16^{\mathrm{INK} 4 \mathrm{a}}$ is a prerequisite for hTERT effects in these cells (Farwell et al, 2000; Kiyono et al, 1998). In addition, the expression of hTERT is re- 
quired, but not sufficient, for the immortalization of CD8+ T lymphocytes (Migliaccio et al, 2000). Moreover, the overexpression of hTERT does not preclude a crisis in mass cultures of normal human fibroblasts after an extended period of proliferation (MacKenzie et al, 2000).

Plasmids encoding various genes known to be involved in carcinogenesis were introduced into freshly isolated, low-passage HPMEC. We found that only cells cotransfected with plasmids encoding hTERT and a plasmid encoding simian virus 40 (SV40) large $T$ antigen could be continuously propagated without undergoing a major crisis. These cells (HPMEC-ST) were cloned and expanded into cell lines. One cell line, HPMEC-ST1.6R, exhibited most of the phenotypic properties of the parental cells. This cell line will be a valuable tool for the study of microvascular endothelial-specific changes in gene expression and for the study of endothelial pathobiology with relevance for pulmonary diseases and pulmonary metastasis.

\section{Results}

\section{Cells Cotransfected with Plasmids Encoding hTERT and SV40-T (HPMEC-ST) Have an Extended Lifespan}

We transfected HPMEC from different donors with various plasmids encoding genes known to be involved in carcinogenesis. These constructs included pSV3 neo, encoding SV40 large T antigen (Southern and Berg, 1982); pBABEhygroPymT, encoding polyoma middle T (PymT) (Sabapathy et al, 1997); pLTRcmyc, encoding human c-myc (Stanton et al, 1983); pcDNA3-T24, encoding the activated human ras T24 gene (Goldfarb et al, 1982); and two constructs encoding hTERT, pC1-neo-hTERT (Counter et al, 1998) and pGRN.145 (Bodnar et al, 1998). To assess the effects of plasmids on HPMEC lifespan, the transfected cells were selected with appropriate drugs, subcultured, and expanded in selective media. The cultures were discontinued when the majority of cells acquired a senescent morphology and were obviously unable to proliferate. Untreated HPMEC cultures became senescent after 10 to 13 passages (21-26 population doublings). This corresponded to approximately 3 months of serial passaging.

The HPMEC cultures transfected with various combinations of oncogenes (myc, ras, myc + hTERT, ras + hTERT, PymT) entered crisis with gradually increased levels of cell death 6 to 8 weeks after transfection and eventually died after reaching the population doubling limit of untreated cells (data not shown). The cells transfected with plasmids pC1-neo-hTERT (Counter et al, 1998) and pGRN.145 (Bodnar et al, 1998) encoding hTERT developed a distinctive senescent morphology and displayed senescence associated $\beta$-galactosidase expression after 32 population doublings (PD) in 5 to 7 months of uninterrupted propagation (Fig. 1C). The cells transfected with plasmid pSV3 neo (Southern and Berg, 1982) succumbed to a crisis 4 months after transfection (24 PD). In

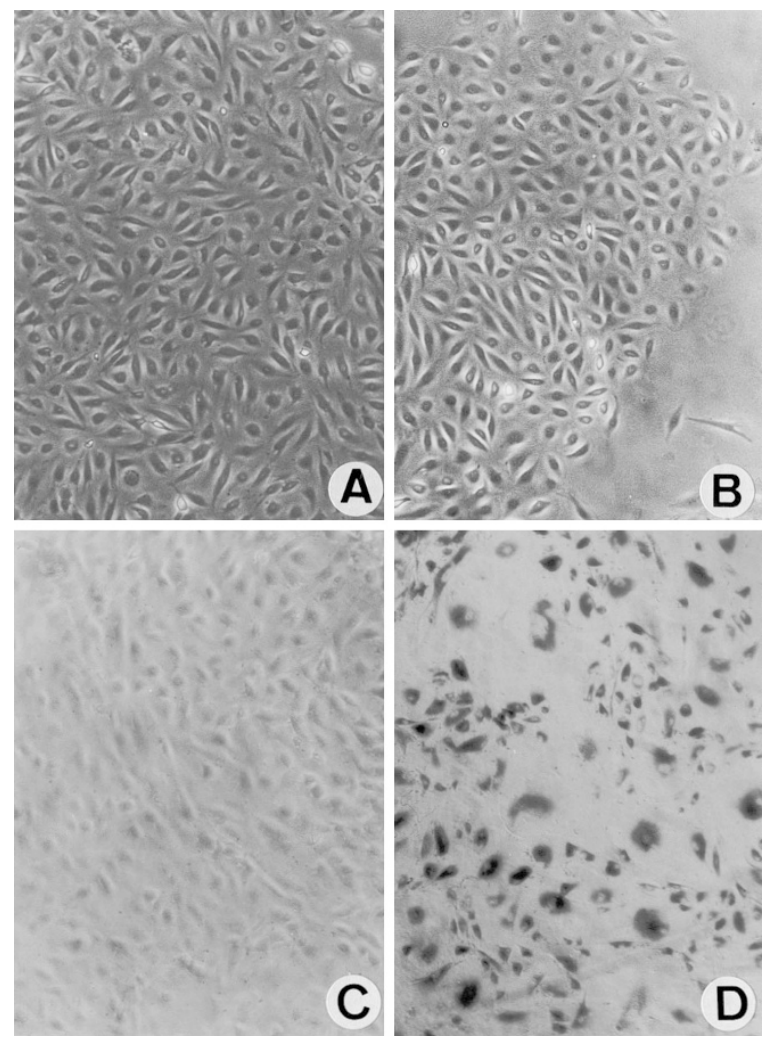

Figure 1.

Human pulmonary microvascular endothelial cells (HPMEC) cultures after cotransfection with plasmids encoding human telomerase reverse transcriptase protein (hTERT) and simian virus 40 (SV40) large T antigen. Morphology of HPMEC-ST1.6R cells after 1 year of continuous propagation. A confluent monolayer exhibiting convex polygonal shape of the cells $(A)$, at preconfluent stage (B). $C$ and D, Expression of senescence-associated $\beta$-galactosidase (SA- $\beta$ gal). No expression of SA- $\beta$ gal was detected in morphologically normal HPMEC-ST1.6R grown in the presence of the selective drug for 40 weeks (28 passages, population doublings [PD] 70) (C). HPMEC transfected with pGRN145hygro and having survived in the presence of selective drug for 38 weeks, 13 passages, PD 41 (D) express SA- $\beta$ gal activity similarly to control senescent human umbilical vein endothelial cells (HUVEC) propagated without selection for 47 weeks, PD 70, 29 passages. Phase contrast photomicrographs at $\times 100$ magnification.

contrast, the HPMEC from two different donors continued to proliferate without exhibiting a major crisis after cotransfection of pSV3 neo and either pC1-neo-hTERT or pGRN.145 giving two populations of cells with extended lifespan (HPMEC-ST1 and HPMEC-ST2).

HPMEC-ST1 were generated after cotransfection of HPMEC (male, 63 years old) with plasmids $\mathrm{pC} 1$-neohTERT and pSV3 neo. The cells have been passaged for 24 months and have reached at least 268 PD. After the cultures continued to proliferate beyond the normal replicative limit of the parental cells, the cells were cloned after 28 passages (PD 53). Twenty single cell-derived clones were isolated, expanded, and subcultured in selective media 1:5 when they reached confluence. Although the HPMEC-ST1 clones were different morphologically, all clones survived for at least 67 PD. The cultures remained density inhibited.

The observation that both hTERT and simian virus 40 (SV40) largeT antigen were required for the extension of 
lifespan was confirmed using HPMEC from a second donor (male, 74 years old). The cells were cotransfected with pSV3 neo and a plasmid pGRN145 (Bodnar et al, 1998). Whereas the untreated cultures became senescent and did not show any sign of growth 3 months after transfection, the cultures transfected with plasmid pGRN145 could be kept in culture for an additional two months but finally became senescent after 24 PD. The cultures cotransfected with both plasmids (HPMEC-ST2) were expanded in selection media containing both G418 and hygromycin. The cells were cloned by limiting dilution after $25 \mathrm{PD}$, and 10 clones were isolated, expanded, and have been continuously passaged 1:5 in selective media for 66 PD.

\section{Cells with Extended Lifespan HPMEC-ST Express the Transfected Sequences}

To verify that the HPMEC cotransfected with pSV3 neo and hTERT plasmids express both exogenous sequences, we screened the transfected cells by reverse transcription-polymerase chain reaction (RTPCR). All HPMEC-ST clones expressed both SV40 large $\mathrm{T}$ antigen and $\mathrm{hTERT}$ sequences. The parental cells were negative (Fig. 2). Immunocytochemical examination indicated that, in contrast to primary isolated endothelial cells, virtually $100 \%$ of HPMECST1.6R cells showed an intense predominantly nuclear expression SV40 large T antigen (not shown).

\section{HPMEC-ST Show Telomerase Activity}

To ascertain that the hTERT sequences in HPMECST1 clones encoded a functional telomerase, the cell lysates of HPMEC-ST1 cells were analyzed using the telomeric repeat amplification protocol (TRAP) assay. The cells of HPMEC-ST1.6R showed telomerase activity in the TRAP assay after 5 months of propagation in selection medium. The level of telomerase expression was comparable with that expressed in HeLa cells. Telomerase activity was undetectable in heatinactivated cell lysates $\left(85^{\circ} \mathrm{C}\right.$ for 10 minutes). Telomerase activity was below the detection level in primary isolated endothelial cells (Fig. 2).

\section{Cells with Extended Lifespan Have Growth Characteristics Similar to HPMEC}

The immortalized cells HPMEC-ST1.6R exhibited a "cobblestone" morphology similar to the parental HPMEC (Fig. 1, A and B). The growth requirements of the cell line HPMEC-ST1.6R were assayed after uninterrupted passaging for more than 1 year in HPMEC medium containing G418 $(50 \mu \mathrm{g} / \mathrm{ml})$. After being transferred from HPMEC medium (20\%FCS + ECGS/heparin), the HPMEC-ST1.6R were able to proliferate in medium lacking ECGS/heparin, although at a much lower rate than in medium containing ECGS/heparin. The growth rate was markedly reduced in medium supplemented with $5 \%$ FCS and the cells failed to grow in medium containing 1\% FCS. (Fig. 3). In the complete medium, the HPMEC-ST1.6R cultures grew to about 3-fold higher densities than the primary HPMEC. Never-
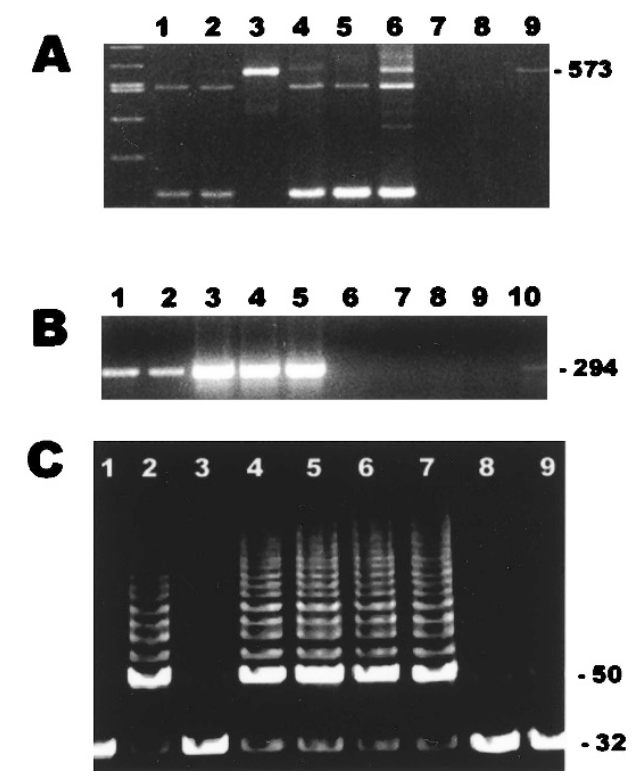

Figure 2.

Expression of exogenous sequences of SV40 large $T$ antigen and hTERT in HPMEC-ST. A, Expression of SV40 large T antigen-related sequences in the course of propagation. RT-PCR analyses. 1, HPMEC-ST1.6R, passage 25 (PD 132); 2 , HPMEC-ST1.6R, passage 10 (PD 96); 3, HPMEC-ST2 pool of drug-selected cells 2 months after transfection; 4 to 6 , three clones of HPMEC-ST2, passage 3 after transfection (PD 51); 7, HPMEC; 8, no DNA; 9, plasmid pSV3 neo (20 pg) giving a fragment of expected size of 573 bp. B, Expression of hTERT in HPMEC-ST. RT-PCR analyses. Both HPMEC-ST1 and HPMEC-ST2 expressed hTERT. The expression was not affected by incubation with lipopolysaccharide from $\mathrm{E}$. coli (LPS, $1 \mu \mathrm{g} / \mathrm{ml}, 37^{\circ} \mathrm{C}, 4$ hours). HPMEC of two different donors (HPMEC-1 and HPMEC-2) did not express hTERT sequences. 1 and 2, Two independent pools of HPMEC-ST2 selected in medium containing both selection drugs, 2 months after transfection; 3 and 4, HPMEC-ST1.6R, 1 year after transfection (PD 100); 5, a clone of HPMEC-ST2, 6 months after transfection; 6 and 7, HPMEC-1; 8 and 9 , HPMEC-2; 10, plasmid pC1 neo-TERT giving a fragment of the expected size of 294 bp. 3, 6, and 8, cells were treated with LPS ( $1 \mu \mathrm{g} / \mathrm{ml}, 37^{\circ} \mathrm{C}, 4$ hours). C, Expression of functional hTERT in HPMEC-ST1. Telomerase activity was assayed with telomeric repeat amplification protocol (TRAP) assay. 1 and 2, HeLa; 3 to 7 , HPMEC-ST1, PD 60; 8 and 9, primary isolated human endothelial cells; 2, 4 to 7 , and 9 , native cells lyzates; 1,3 , and 8 , the lysates were heated at $85^{\circ} \mathrm{C}$ for 10 minutes.

theless, the cultures remained density inhibited. The growth requirements of HPMEC-ST1.6R were similar to those of primary isolated HPMEC (Fig. 3). The growth rate of primary isolated HPMEC is, however, determined by the time the cells are in culture, the cells in a higher passage proliferate typically slower, and the cultures reaching lower saturation densities than the freshly isolated cells (not shown). The saturation densities of HPMEC after 4 weeks in culture, which we used in these experiments, may have been lower than those of cells immediately after the isolation. The comparison of growth requirements of HPMEC-ST1.6R and parental HPMEC suggests that HPMEC-ST1.6R retained normal endothelial growth control mechanisms but acquired the capacity to proliferate normally even after prolonged passaging in vitro.

\section{HPMEC-ST Express Constitutive Phenotypic Endothelial Markers}

A constitutive expression of VWF and CD31 is characteristic of endothelial cells (Albelda et al, 1990; 


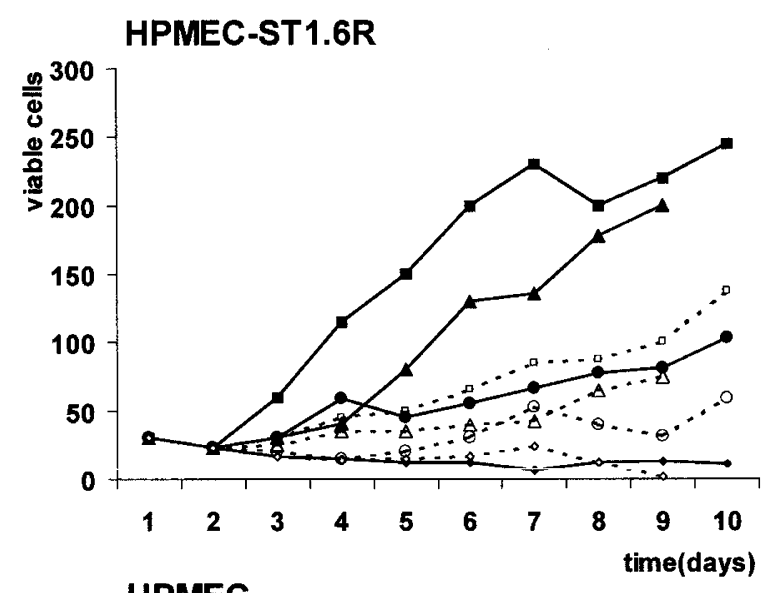

HPMEC

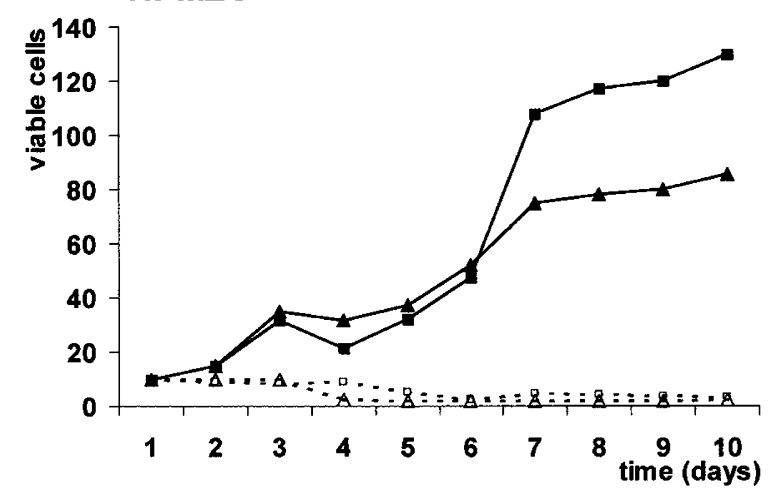

Figure 3.

Growth requirements of HPMEC-ST1.6R and HPMEC. HPMEC at PD 7 and HPMEC-ST1.6R at PD 168 were plated in medium containing various concentrations of FCS $(20 \%$, squares; $10 \%$, triangles; $5 \%$, circles; and $1 \%$, diamonds) in the presence (plain symbols, full lines) or absence (empty symbols, interrupted lines) of endothelial cell growth supplement (ECGS, $50 \mu \mathrm{g} / \mathrm{ml}$ )/ heparin $(25 \mu \mathrm{g} / \mathrm{ml})$. Cell numbers are average of two wells on a 12-well plate $\times 10^{3}$. Detached cells were counted after trypan blue vital stain.

Hewett and Murray, 1993). We screened the single cell-derived clones of HPMEC-ST1 for expression of vWF and CD31 by RT-PCR. All HPMEC-ST1 clones expressed cDNA for both CD31 and vWF. In contrast, no clones of HPMEC-ST2 expressed vWF. The expression of CD31 was detected in the majority of HPMEC-ST2 clones. An incubation of cells with lipopolysaccharide from E. coli (LPS) under conditions stimulating a proinflammatory reaction $(1 \mu \mathrm{g} / \mathrm{ml}, 4$ hours) had no effect on the expression of vWF or CD31 (Fig. 4).

To verify that the transcripts detected in RT-PCR analyses encode functional proteins, we analyzed several clones of HPMEC-ST1 immunocytochemically. The proportion of cells showing a significant expression of vWF varied from less than $5 \%$ to about $50 \%$ among the clones of HPMEC-ST1. The expression of CD31 was more consistent, the majority of clones expressed CD31 in the majority of cells. (Fig. 4A). A selected clone based on a high expression of vWF, HPMEC-ST1.6R, preserved CD31 expression in virtually all cells after 1 year of continuous propagation. A strong expression of vWF could be demonstrated immunocytochemically in most of cells of this particular clone. The proportion of cells showing a

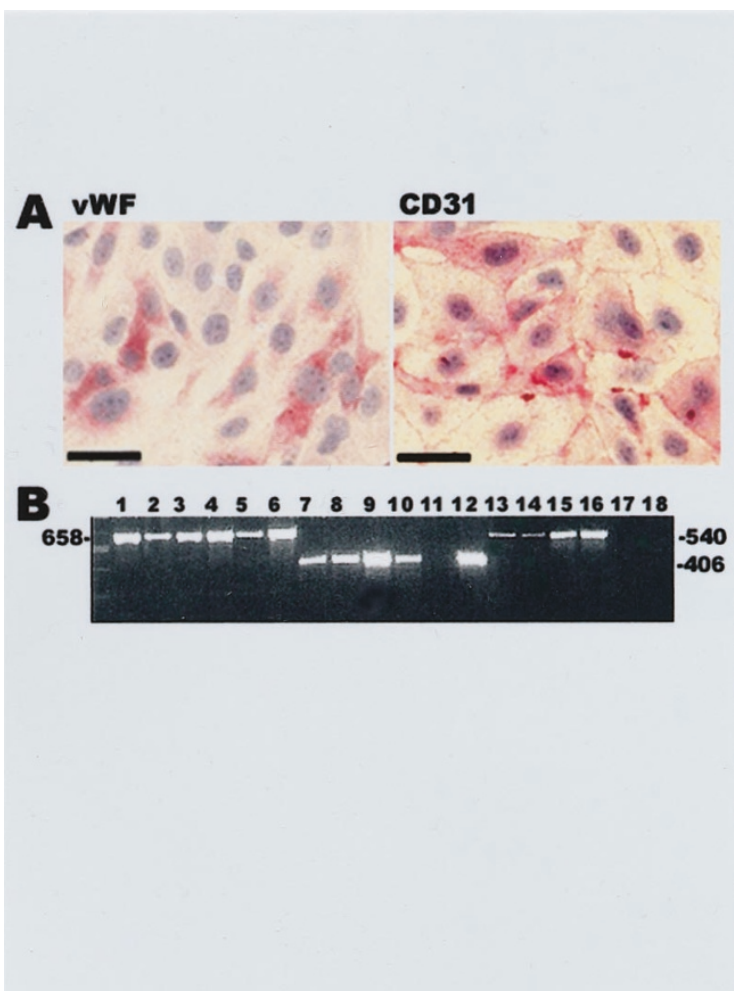

\section{Figure 4.}

Characterization of HPMEC-ST1.6R by immunocytochemical staining (A) and RT-PCR analyses (B). A, HPMEC-ST1.6R, PD 156, express both intracytoplasmatic von Willebrand factor (VWF) and membrane-associated CD31. The specificity of staining was controlled both with isotype control and using HeLa cells as a negative and HUVEC in an early passage as a positive control, respectively. Bar, $50 \mu \mathrm{m}$. B, RT-PCR analyses showing a constitutive expression of VWF and CD31 in HPMEC-ST1.6R, HPMEC-ST2 and in parental HPMEC. HPMEC-ST1.6R, passage 25 (PD 132) $(1,2,7,8,13,14)$, incubated $(1,7,13)$ or not $(2,8,14)$ with LPS $(1 \mu \mathrm{g} / \mathrm{ml}, 4$ hours); HPMEC $(3,4,9,10$, $15,16)$, incubated with $\operatorname{LPS}(3,9,15)$, not incubated with $\operatorname{LPS}(4,10,16)$; clone HPMEC-ST2.1, no LPS $(5,11,17)$; clone of HPMEC-ST2.2, no LPS (6, 12, 18). Lanes 1 to 6: actin (658 bp); lanes 7 to 12: CD31 (406 bp); lanes 13 to $18:$ vWF (540 bp)

strong expression of vWF remained stable after 1 year of uninterrupted passaging.

\section{HPMEC-ST1.6R Respond to Proinflammatory Stimuli}

Endothelial cells typically respond to the proinflammatory stimuli, tumor necrosis factor-alpha (TNF $\alpha$ ), bacterial LPS, and interleukin $1 \beta($ IL1- $\beta$ ) by induction of the production of cellular adhesion molecules (CAM), which are crucial for the interaction of endothelial cells with other cell types (Bevilacqua et al, 1987; Dustin and Springer, 1988; Osborn et al, 1989). The expression of intercellular cell adhesion molecule-1 (ICAM-1), vascular cell adhesion molecule-1 (VCAM-1), and E-selectin (E-sel) were analyzed by enzyme immunoassays. We observed that the up-regulation of cell adhesion molecules in HPMEC-ST1.6R after stimulation with proinflammatory stimuli followed the same pattern as in the parental cells HPMEC, showing a typical transient induction of E-sel production as well as an increased production of ICAM-1 and VCAM-1. Freshly isolated HUVEC manifested a greater respon- 
siveness than either low passage HPMEC or HPMECST1.6R (Fig. 5).

In contrast to the available endothelial cell lines EA-hy.926 (Edgell et al, 1983), EVLC2 (van Leeuwen et al, 2000), HAEND (Hoover et al, 1993), ISO-HAS (Masuzawa et al, 1999), and HMEC-1 (Ades et al, 1992), the HPMEC-ST1.6R preserved the full responsiveness of primary isolated endothelial cells to proinflammatory stimuli (manuscript in preparation).

\section{HPMEC-ST1.6R Demonstrate Angiogenic Characteristics}

The capacity to organize into tubule-like networks with branching morphology in response to a matrix, which mimics the physical and functional properties of basement membrane (Matrigel), define endothelial functions of primary cells propagated in vitro (Lawley and Kubota, 1989). Morphogenetic responses were evaluated by exposing HUVEC, HPMEC, HPMEC-ST1.6R (PD 170), and HeLa cells to Matrigel. HPMEC-ST1.6R, HPMEC, and HUVEC responded similarly by forming "angiogenic webs" on matrigel. The response of ISO-HAS was less obvious, and the epithelial cell line HeLa formed a regular monolayer and failed to

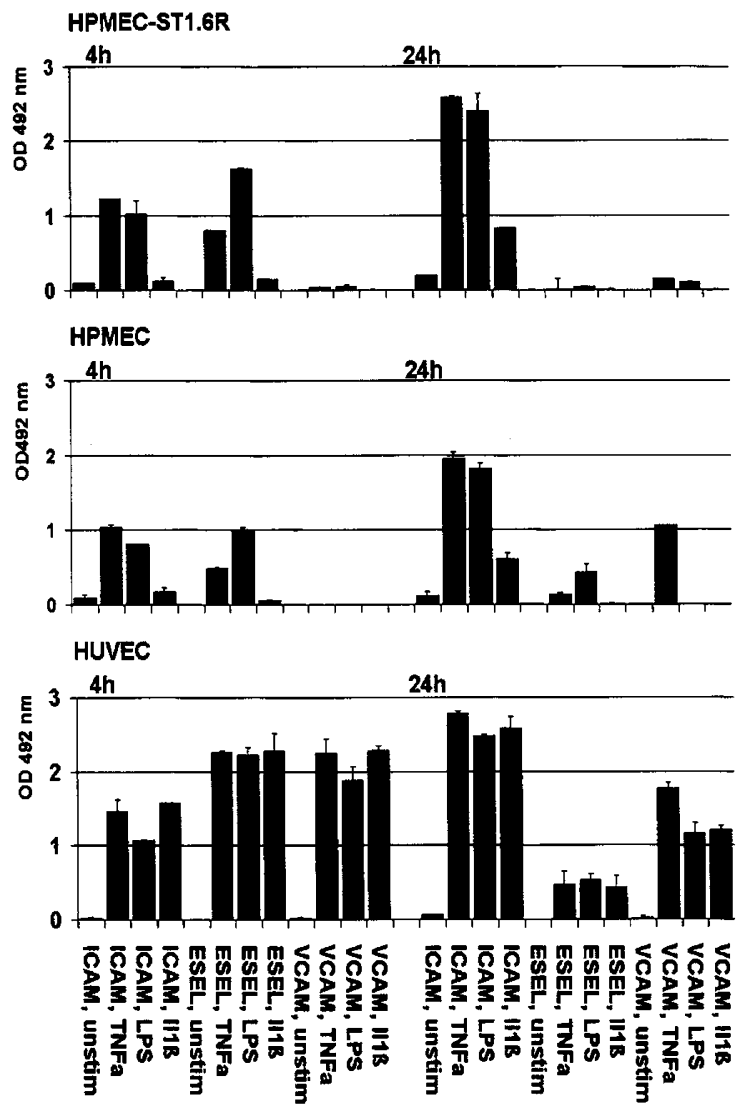

Figure 5.

Comparison of intercellular adhesion molecule-1 (ICAM-1), vascular cell adhesion molecule-1 (VCAM-1), and E-selectin expression in HPMEC-ST1.6R, HPMEC, and HUVEC. Expression of cell adhesion molecules in HPMEC-ST1.6R, 8 months after transfection, PD 86, compared with the parental cells, HPMEC, passage 5, and HUVEC, passage 3 . The cells were exposed to TNF $\alpha(300 \mathrm{U} / \mathrm{ml})$, LPS $(1 \mu \mathrm{g} / \mathrm{ml})$, and interleukin-1 $\beta$ (IL-1 $\beta, 100 \mathrm{U} / \mathrm{ml})$ for 4 and 24 hours. Results of two experiments; the data represent the mean $\pm \mathrm{SD}, n=3$. form tube-like structures (Fig. 6). This demonstrated that the HPMEC-ST1.6R preserved the differentiated phenotype.

\section{HPMEC-ST1.6R are Not Tumorigenic}

Normal proliferation control is perturbed in human cells having the capacity to proliferate indefinitely in vitro. The immortalization may result in tumorigenic conversion. Although the HPMEC-ST1.6R cultures preserved density-inhibited growth and proliferated very slowly in medium with reduced serum concentration, the possibility existed that tumorigenic cells may have been selected upon continuous propagation for more than one year. Therefore, we tested HPMECST1.6R for their capacity to grow when implanted subcutaneously into nude mice. Whereas the control human colon adenocarcinoma cells HT-29 developed large tumors at the injection site within 2 weeks after injection, the mice transplanted with HPMEC-ST1.6R did not develop palpable tumors even after 1 year. The mice were killed 1 year after the injection of cells. During an autopsy, livers, lungs, and injection sites were thoroughly examined. Neither the macroscopical nor histological examination after a staining with hematoxylin-eosin revealed any evidence of tumor formation in the livers, lungs, or anywhere in the flanks of the mice (not shown). We found no other suspicious site of potential distant metastasis. Thus, the immortalization of HPMEC-ST1.6R did not result in a tumorigenic conversion of these cells.

\section{Discussion}

In the present paper, we demonstrate that immortalized cells can be derived from human adult pulmonary microvascular endothelial cells after cotransfection with a plasmid encoding a telomerase gene and a plasmid encoding the SV40 large T antigen. To date, the cells have maintained a normal growth rate for 24 months and express the phenotype of primary cells. The cells exhibit contact inhibition, show normal endothelial morphology, proliferate very slowly in a medium with reduced serum content, and require ECGS for proliferation.

Cell immortalization is a result of a deregulation in complex mechanisms controlling cell proliferation. There is no general concept that would take into account all control mechanisms that may be involved and events that may overrule normal controls. We did not observe a major period of crisis in cultures of HPMEC-ST generated by simultaneous introduction of plasmids encoding hTERT and SV40 large T antigen in the course of 24 months of regular passaging. SV40 large $T$ antigen has been extensively used to immortalize a wide variety of human cell types (Bryan and Reddel, 1994). SV40-induced immortalization typically proceeds in two discrete stages. The cells, having acquired an extended lifespan presumably because of a shutdown of the products of tumor suppressor genes of $p 53$ and retinoblastoma by SV40 large T antigen, proliferate beyond a limit at which normal 

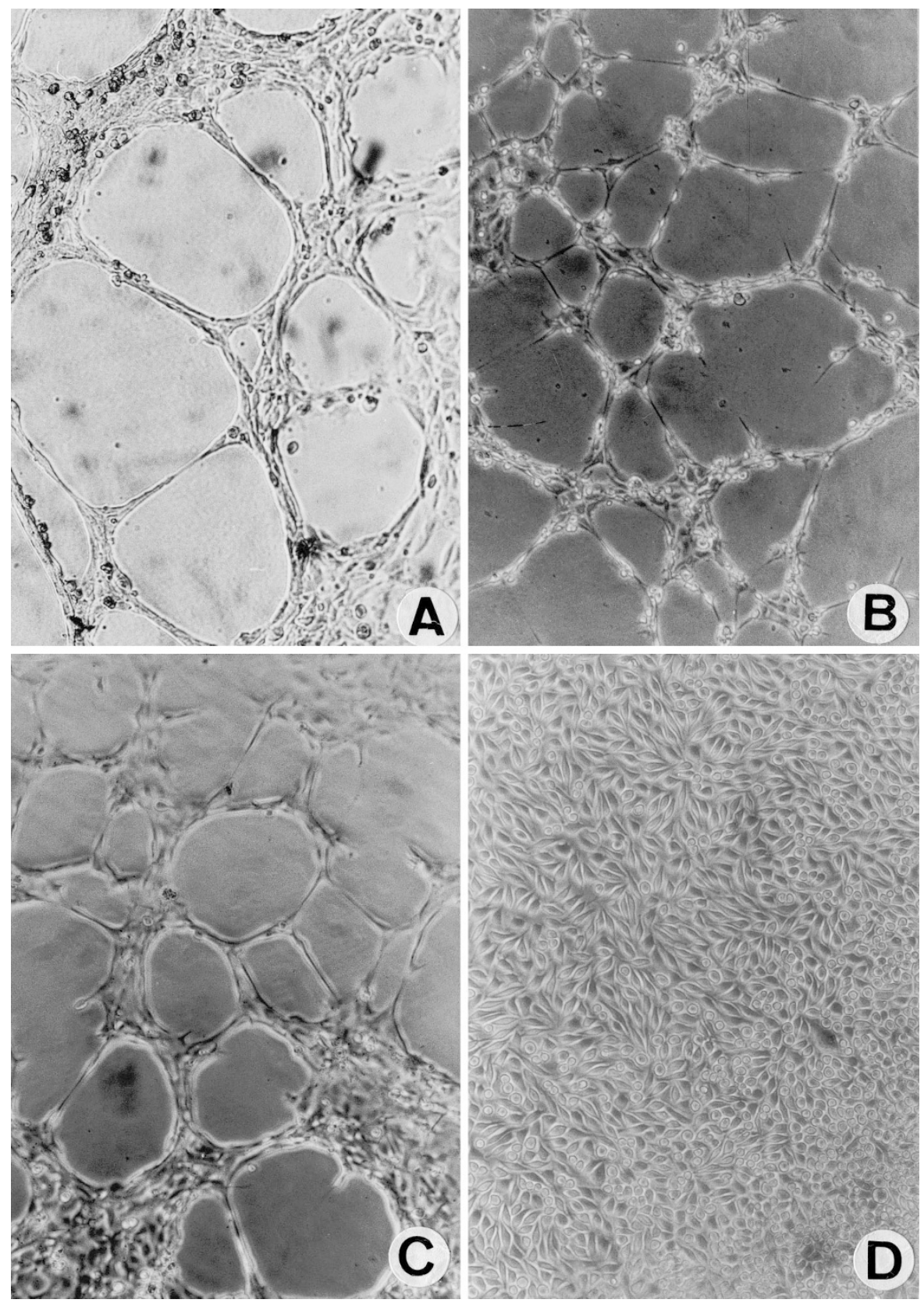

Figure 6.

Morphogenetic response of HPMEC-ST on Matrigel basement membrane matrix. Early passage HUVEC (A), HPMEC (B), and HPMEC-ST1.6R, 15 months after transfection (C), formed angiogenic webs. HeLa (D) were used as negative control. The reaction was evaluated after 8 hours. Phase contrast, $\times 50$ and $\times 100$ magnification.

cells undergo senescence. Only a small fraction of these cells survive a subsequent crisis and proliferate indefinitely. Furthermore, the introduction of telomerase into cells expressing SV40 large T antigen enabled human fibroblasts and embryonic kidney and pancreatic cells to escape from crisis (Counter et al, 1998; Halvorsen et al, 1999; Zhu et al, 1999).

It was previously reported that the lifespan of primary neonatal human dermal microvascular endothelial cells (HDMEC) could be extended without affecting the differentiated phenotype by ectopic expression of hTERT in these cells (Yang et al, 1999). According to our results, the HPMEC isolated from adult donors older than 50 years could be immortalized only after cotransfection of plasmids encoding hTERT and SV40 large $T$ antigen. Since the mean terminal restriction fragment length of endothelial cells in culture was demonstrated to show an inverse relationship between donor age and telomere length (Chang and Harley, 1995), it is possible that the ectopic expression of hTERT is only sufficient to the extend lifespan of neonatal cells having long telomeres, but additional genetic events may be necessary to immortalize endothelial cells isolated from more elderly donors.

The immortalization of human pulmonary endothelial microvascular cells is an infrequent event. The low 
incidence of tumors of endothelial origin (angiosarcoma) may reflect a resistance of endothelial cells to tumorigenic conversion. In addition, the pulmonary microvascular endothelium may consist of adapted cells that may be especially resistant to genetic changes because of their location and high exposure to external stimuli.

The cell line HPMEC-ST1.6R preserved the major characteristics of primary endothelial cells and expressed both constitutive and inducible endothelial cell markers. In contrast, in almost all reports on SV40 $T$ antigen-immortalized endothelial cells, the growth characteristics of primary cells were changed or only some of the characteristic endothelial cell markers remained (Ades et al, 1992; Fickling et al, 1992; Gimbrone and Fareed, 1976; Hohenwarter et al, 1994; Reznikoff and DeMars, 1981; Wautier et al, 1999). The detrimental effects of immortalization on the expression of endothelial characteristics were also observed in a commonly used cell line of endothelial origin EA.hy926 (a fusion product between HUVEC and lung carcinoma) (Edgell et al, 1983) and in HUVEC immortalized with human papilloma virus-16 (HPV-16) oncoproteins E6/E7 (Burger et al, 1998; Fontijn et al, 1995).

The two populations of immortalized HPMEC were generated using cells from different donors. This suggests that the cooperation between hTERT and SV40 large $T$ antigen is essential for the immortalization of HPMEC. The observation that cell lines HPMEC-ST2 failed to express some endothelial characteristics suggests that the genetic background of cells may be of importance for the preservation of phenotype in immortalized cells.

We are currently examining the development of telomere length in the process of immortalization of HPMEC-ST1.6R and examining additional functional characteristics of the microvascular endothelial cell line.

HPMEC-ST1.6R retained endothelial cell phenotypic characteristics by essentially all commonly accepted criteria, including the angiogenic response and the ability to up-regulate cell adhesion molecules upon exposure to proinflammatory stimuli. Although the HPMEC-ST1.6R obviously surpassed the immortalization limits, they did not manifest changes typically associated with oncogenic transformation. These cells will be a useful tool in studies of adult microvascular endothelium of lung and may replace primary cells in various assays systems.

\section{Materials and Methods}

\section{Culture of Endothelial Cells}

HUVEC were isolated from umbilical veins according to a published method (Jaffe et al, 1973) and propagated in medium M199 (Sigma-Aldrich, Irvine, United Kingdom) supplemented with fetal calf serum (FCS, 20\%; Invitrogen, Carlsbad, California), Glutamax (2 $\mathrm{mm}$, Invitrogen), Pen/Strep (100U/100 $\mu \mathrm{g} / \mathrm{ml}$, Invitrogen), sodium heparin $(25 \mu \mathrm{g} / \mathrm{ml}$, Sigma-Aldrich), and endothelial growth factor supplement (ECGS, $25 \mu \mathrm{g} /$ ml; Becton Dickinson, Bedford, Massachusetts). For culture of HPMEC, the medium was supplemented with $50 \mu \mathrm{g} / \mathrm{ml}$ ECGS. The cells were cultured on tissue culture plasticware precoated with gelatin $(0.2 \%$, Sigma-Aldrich). The culture medium was changed 2 to 3 times weekly. The cells were detached using trypsinEDTA (Invitrogen). The cells with extended lifespan were cloned in selective medium both by limiting dilution on 96-well plates and by the plating of about 20 cells on a $100-\mathrm{mm}$ dish and allowing colonies to develop.

For proliferation assays, the cells were plated on gelatin-coated 12-well plates and propagated in media containing reduced serum with or without ECGS/ heparin supplementation. On the following days, the cells were detached and counted after staining with trypan blue. Cells of two wells were counted. The medium was changed every 2 days.

\section{Isolation of Human Pulmonary Microvascular Endothelial Cells}

HPMEC were isolated from lungs resected from adult patients with malignant tumors. Normal lung tissue from the subpleural region $(1 \mathrm{~g})$ was removed and minced. The tissue fragments were then incubated under gentle agitation with dispase $(0.4 \%$, Cell Systems, St. Catharinen, Germany) at $4^{\circ} \mathrm{C}$ for 12 hours. Cell debris and erythrocytes were removed by filtration through a 100- $\mu \mathrm{m}$ nylon mesh strainer (Becton Dickinson Plasticware, Franklin Lanes, New Jersey). The tissue fragments were digested with elastase $(60$ $\mathrm{U} / \mathrm{ml}$, Cell Systems), trypsin (0.025\%, Cell Systems), and EDTA (0.9 mm, Sigma-Aldrich) for 30 minutes at $37^{\circ} \mathrm{C}$ after which the suspension was homogenized by pipetting. The homogenate was filtered first through a $100-\mu \mathrm{m}$ mesh strainer and subsequently through a $40-\mu \mathrm{m}$ mesh strainer and pelleted by centrifugation (173g for 10 minutes). The cell pellets were resuspended in HPMEC medium containing M199, 20\% FCS, Glutamax (2 mm), Pen/Strep (100U/100 $\mu \mathrm{g} / \mathrm{ml})$, heparin $(50 \mu \mathrm{g} / \mathrm{ml})$, and ECGS $(50 \mu \mathrm{g} / \mathrm{ml})$ and cultivated on 6 -well plates precoated with gelatin $(0.2 \%)$ for several days until subconfluent. Endothelial cells expressing CD31 were isolated using magnetic beads (Dynal, Oslo, Norway) according to the instructions of the manufacturer. The medium was replaced every 2 to 3 days, and the subcultures were obtained by trypsin/EDTA treatment of confluent monolayers at a splitting ratio of $1: 3$.

\section{Transfections and Selection of Transfected Cells}

Transfections were performed using Lipofectamine Plus (Invitrogen) according to the instructions of the manufacturer. Briefly, subconfluent overnight monolayers $\left(1 \times 10^{6}\right.$ cells/well of a 6 -well plate) were exposed to complexes of plasmid $(1-10 \mu \mathrm{g})$, PLUS reagent $(6 \mu \mathrm{l})$, and Lipofectamine $(4 \mu \mathrm{l}) / 100 \mu \mathrm{l}$ for 3 hours. Efficiency of transfection was verified in transient transfections using a plasmid encoding Green Fluorescent Protein (GFP). Approximately $30 \%$ of 
treated cells transiently expressed GFP after 24 hours. Stably transfected cells were selected and propagated in media containing either G418 $(50 \mu \mathrm{g} / \mathrm{ml}$, Invitrogen) or Hygromycin (12 $\mu \mathrm{g} / \mathrm{ml}$, Invitrogen) beginning 2 weeks after transfection. The selection was maintained throughout the culture of transfected cells.

Two different versions of hTERT encoding vectors were used to introduce $h T E R T$ gene in HPMEC. The expression of hTERT was driven from the cytomegalovirus (CMV) promoter in pC1-neo-hTERT (Counter et al, 1998). The hTERT gene was under the control of mouse myeloproliferative virus long terminal repeat MPSV LTR in PGRN145, which confers resistance of the cells to hygromycin (Bodnar et al, 1998). The SV3 neo plasmid was obtained from American Type Culture Collection (ATCC, Manassas, Virginia).

\section{RT-PCR Reaction}

Total cellular RNA was isolated using QIA-shredders and RNeasy RNA Isolation Kit (QIAGEN GmbH, Hilden, Germany). RT-PCR was performed using the Omniscript RT-kit (QIAGEN GmbH) and PCR supermix (Invitrogen). All RNA samples were treated with DNasel (Rnase-free DNase, QIAGEN GmbH). The cDNA sequences were obtained from the GenBank Database of the National Center for Biotechnology Information (NCBI) of the National Institutes of Health (Bethesda, Maryland). PCR primer-sequences, the sizes of amplified fragments, and annealing temperatures are listed in Table 1. The conditions for amplification were as follows: denaturation of template was performed at $95^{\circ} \mathrm{C}$ for 2 minutes, followed by 30 amplification cycles $\left(95^{\circ} \mathrm{C}\right.$ for 30 seconds, annealing temperature for 30 seconds, $72^{\circ} \mathrm{C}$ for 30 seconds), followed by a $72^{\circ} \mathrm{C}$ step of 8 minutes. PCR products were separated by a $1.5 \%$ to $2 \%$ agarose gel in TBE buffer and visualized with ethidium bromide. Authenticity of products was verified by positive (plasmid containing the relevant sequences) and negative (cDNA of cells lacking the relevant sequences) controls.

\section{Senescence-Associated $\beta$-Galactosidase Staining}

The endothelial cells were grown to $60 \%$ to $80 \%$ confluence on gelatin-coated plastic Lab-Tek permanox chamber slides (Nalge Nunc International, Naperville, Illinois), washed in phosphate-buffered saline, and then fixed in $0.5 \%$ glutaraldehyde for 10 minutes. Staining for SA- $\beta$-gal expression was carried out according to the protocol established by Dimri et al (1995). Color micrographs were taken with the inverted microscope (Leica, Bensheim, Germany).

\section{Immunocytochemistry}

The cells were grown overnight on fibronectin-coated ( $5 \mu \mathrm{g} / \mathrm{ml}$, Roche Molecular Biochemicals, Mannheim, Germany) culture slides (Falcon-Becton Dickinson, Franklin Lakes, New Jersey), fixed with paraformaldehyde (3.7\%), permeabilized with $0.5 \%$ Triton-100 (for VWF and SV40 large T antigen staining), and stained with ABC-Complex/AP (DAKO, Hamburg, Germany) according to the instructions of the manufacturer. Primary antibodies were VWF (A0082, 1:6000, DAKO), CD31 (M0823, 1:50, DAKO), and SV40 T (Ab-2, DP02, 1:100, Oncogene Research Products, Boston, Massachusetts). Secondary antibodies were biotinylated anti-mouse IgG (BA-200, 1:200, Vector Laboratories, Burlingame, California) and anti-rabbit IgG (1:200, Vector Laboratories). The nuclei were counterstained with hematoxylin according to standard protocols.

\section{TRAP Assay}

The TRAP assay was performed using the Telomerase detection kit (Oncor, Gaithersburg, Maryland) according to the instructions of the manufacturer. The amplified fragments were separated on a $10 \%$ acrylamide gel and stained with Sybr Green I nucleic acid gel stain (Molecular Probes, Leiden, The Netherlands). Protein concentration in the cell lysates was determined using the Bio-Rad protein assay (Bio-Rad, München, Germany) and 1000 to 5000 cell equivalents were analyzed in each assay. Heat-treated controls from each sample (heated for 10 minutes at $85^{\circ} \mathrm{C}$ ) were included

Table 1. Primers Used for Polymerase Chain Reaction

\begin{tabular}{|c|c|c|c|}
\hline $\begin{array}{c}\text { Target } \\
\text { (GeneBank accession } \\
\text { number/reference) }\end{array}$ & $\begin{array}{c}\text { Size of } \\
\text { amplified } \\
\text { fragment (bp) }\end{array}$ & $\begin{array}{l}\text { Annealing } \\
\text { temperature }\end{array}$ & Primer sequence \\
\hline $\begin{array}{l}\text { VWF } \\
\text { (NM_000552.1) }\end{array}$ & 540 & $55^{\circ} \mathrm{C}$ & $\begin{array}{l}\text { 5'-AGT TCA TGG AGG AGG TGA TTC AGC-3' } \\
\text { 5'-AGC CAT CCA GGA GAA GGA TCA CG-3' }\end{array}$ \\
\hline $\begin{array}{l}\text { CD31 } \\
(L 34640)\end{array}$ & 403 & $60^{\circ} \mathrm{C}$ & $\begin{array}{l}\text { 5'-TCC CAG GCC AAA ATG TTA AAG TGA G-3' } \\
\text { 5'-GAT CAA GAG AGC AAT GAT CAC TCC-3' }\end{array}$ \\
\hline $\begin{array}{l}\text { actin } \\
\text { (AB004047) }\end{array}$ & 658 & $65^{\circ} \mathrm{C}$ & $\begin{array}{l}\text { 5'-AGC ATT TGC GGT GGA CGA TGG AF-3' } \\
\text { 5'-GAC CTG ACT GAC TAC CTC ATG A-3' }\end{array}$ \\
\hline $\begin{array}{l}\text { hTERT } \\
\text { (AF018167.1) }\end{array}$ & 294 & $65^{\circ} \mathrm{C}$ & $\begin{array}{l}\text { 5'-CAC CTC ACC CAC GCG AAA AC-3' } \\
\text { 5'-CGC AAA CAG CTT GTTB CTC CAT GTC-3' }\end{array}$ \\
\hline $\begin{array}{l}\text { SV40-T } \\
\text { (Carbone et al, 1996) }\end{array}$ & 574 & $65^{\circ} \mathrm{C}$ & $\begin{array}{l}\text { 5'-CTT TGG AGG CTT CTG GGA TGC AAC T-3' } \\
\text { 5'-GCA TGA CTC AAA AAA CTT AGC AAT TCT G-3' }\end{array}$ \\
\hline
\end{tabular}

VWF, von Willebrand factor; CD31, platelet endothelial cell adhesion molecule; hTERT, human telomerase reverse transcriptase protein; SV40, simian virus 40. 
to rule out false-positive signals caused by PCR artifacts.

\section{Quantification of Expression of Cell Adhesion Molecules in Endothelial Cells by Enzyme Immunoassay (CAM- EIA)}

Cells were seeded $\left(2 \times 10^{4}\right.$ cells/well) onto fibronectincoated (5 $\mu \mathrm{g} / \mathrm{ml}$, Roche Molecular Biochemicals) 96well microtiter plates and grown for 24 hours before the monolayers were stimulated with TNF $\alpha(300 \mathrm{U} / \mathrm{ml}$, Sigma Chemical, St. Louis, Missouri), LPS (1 $\mu \mathrm{g} / \mathrm{ml}$, Sigma), and human interleukin-1 $\beta$ (IL-1 $\beta, 100 \mathrm{U} / \mathrm{ml}$; Strathmann Biotech, Hannover, Germany) for 4 and 24 hours. After stimulation the cells were washed twice with PBS $\left(37^{\circ} \mathrm{C}\right)$, fixed in methanol/ethanol (2:1) for 15 minutes, washed 3 times with PBS, and incubated first with blocking buffer (Roche Molecular Biochemicals), containing $1 \% \mathrm{H}_{2} \mathrm{O}_{2}$ at $37^{\circ} \mathrm{C}$ for 60 minutes, followed by an incubation with primary antibody at $37^{\circ} \mathrm{C}$ for 45 minutes. Primary antibodies were as follows: monoclonal anti-E-selectin antibody (100 $\mu \mathrm{g} / \mathrm{ml}$, BMS 110; Bender, Vienna, Austria), monoclonal anti-ICAM-1 antibody $(100 \mu \mathrm{g} / \mathrm{ml}$, BMS 108; Bender MedSystems, Vienna, Austria), or anti-VCAM-1 antibody $(100 \mu \mathrm{g} / \mathrm{ml}$, Southern Biotechnology Associates, Birmingham, Alabama). After three washes with PBS, the cells were exposed to secondary antibody, biotinylated goat-anti-mouse IgG1 (Amersham Life Science, Freiburg, Germany). Signals were enhanced by the biotin-streptavidin system (Amersham). Color reaction was performed using peroxidase-catalyzed o-phenylenediamine (Sigma). The reaction was stopped by the addition of $3 \mathrm{M} \mathrm{HCl}$. Light extinction was determined with ELISA reader at $492 \mathrm{~nm}$. The evaluation of the data was performed with the software assistance of the ELISA Reader Genesis Program (Customized Applications, Inc., Chicago Heights, Illinois).

\section{Matrigel-Based Angiogenesis Assay}

Matrigel (Becton Dickinson) was allowed to thaw on ice overnight and was diluted 1:3 in serum-free cell culture medium M199. $100 \mu$ l of diluted Matrigel were layered onto a prechilled well of a 24-well plate and then incubated at $37^{\circ} \mathrm{C}$ for 30 minutes, until solidified. HUVEC, ISO-HAS (Masuzawa et al, 1999) or HPMEC-ST $\left(1 \times 10^{5}\right.$ or $5 \times 10^{4}$ cells $)$ were resuspended in M199 with 20\% fetal bovine serum, 25 units $/ \mathrm{ml}$ heparin, $50 \mu \mathrm{g} / \mathrm{ml}$ endothelial cell growth supplement (Becton Dickinson), pipetted onto the solidified matrix, and allowed to incubate at $37^{\circ} \mathrm{C}$ in a $5 \% \mathrm{CO}_{2}$ environment. The epithelial cell line, HeLa, was used as negative control. Development of capillary-like networks and tubular structures were evaluated after 8 and 20 hours. The plates were photographed using a Leica inverted microscope.

\section{Tumorigenicity Assay}

The HPMEC-ST1.6R cells were detached with trypsinEDTA, washed with PBS, resuspended at $1 \times 10^{8}$ cells $/ \mathrm{ml}$, and $0.25 \mathrm{ml}$ of cell suspension were subcu- taneously injected on each side into the rear flanks of two 7 week-old nude mice (CD-I nu; Charles River, Sulzfeld, Germany). The human colon adenocarcinoma cell line HT-29 (Fogh and Trempe, 1975) was used as a positive control. The mice were examined for tumor development weekly. The animals were killed for histological analysis at week 5 (positive control) or 1 year (HPMEC-ST1.6R) after subcutaneous injection. The mice were examined in a careful autopsy for potential distant metastases. The injection sites, lungs, and livers were examined histologically after hematoxylin-eosin staining.

\section{Acknowledgements}

We are grateful to Dr. R. Weinberg and the Geron Corporation for providing the plasmids encoding hTERT, pCl-neo-hTERT, and pGRN 145. We also thank Ms. C. Ziegelmayer for her excellent technical assistance.

\section{References}

Ades E, Candal F, Swerlick R, George V, Summers S, Bosse D, and Lawley T (1992). HMEC-1: Establishment of an immortalized human microvascular endothelial cell line. J Invest Dermatol 99:683-690.

Albelda S, Oliver P, Romer L, and Buck C (1990). EndoCAM: A novel endothelial cell-cell adhesion molecule. J Cell Biol 110:1227-1237.

Bevilacqua M, Pober L, Mendrick, Cotran RS, and Gimbrone MA Jr (1987). Identification of an inducible endothelialleukocyte adhesion molecule. Proc Natl Acad Sci USA 84: 9238-9242.

Bodnar A, Ouellette M, Frolkis M, Holt S, Chiu C, Morin G, Harley C, Shay J, Lichtsteiner S, and Wright W (1998). Extension of life-span by introduction of telomerase gene into normal human cells. Science 279:349-352.

Bryan T and Reddel R (1994). SV40-induced immortalization of human cells. Crit Rev Oncog 5:331-157.

Burger A, Fiebig M, Kuettel M, Lautenberger J, Kung H-F, and Rhim J (1998). Effects of oncogene expression on telomerase activation and telomere length in human endothelial, fibroblast and prostate epithelial cells. Int J Oncology 13:1043-1048

Carbone M, Rizzo P, Procopio A, Giuliano M, Pass $H$, Gebhardt M, Mangham C, Hansen M, Malkin D, Bushart G, Pompetti F, Picci P, Levine A, Bergsagel J, and Garcea R (1996). SV40-like sequences in human bone tumors. Oncogene 13:527-535.

Chang E and Harley C (1995). Telomere length and replicative aging in human vascular tissue. Proc Natl Acad Sci USA 92:11190-11194.

Cines D, Pollak E, Buck CA, Loscalzo J, Zimemrman G, McEver R, Pober J, Wick T, Konkle B, Schwartz B, Barnathan E, McCrae K, Hug B, Schmidt A, and Stern D (1998). Endothelial cells in physiology and the pathophysiology of vascular disorders. Blood 91:3527-3561.

Counter C, Hahn W, Wei W, Caddle S, Beijersbergen R, Lansdorp P, Sedivy J, and Weinberg R (1998). Dissociation among in vitro telomerase activity, telomere maintenance, 
and cellular immortalization. Proc Natl Acad Sci USA 95: 14723-14728.

Dimri GP, Lee X, Basile G, Acosta M, Scott G, Roskelley C, Medrano EE, Linskens M, Rubelj I, and Pereira-Smith O (1995) A biomarker that identifies senescent human cells in culture and in aging skin in vivo. Proc Natl Acad Sci USA 92:9363-9367.

Drexler H (1999). ECV304 (endothelial) is really T24(bladder carcinoma): Cell line cross contamination at source. In Vitro Cell Dev Biol 35:558-559.

Dustin $M$ and Springer $T$ (1988). Lymphocyte functionassociated antigen (LFA-1) interacting with intercellular adhesion molecule-1 (ICAM-1) is one of at least three mechanisms forlymphocyte adhesion to culture endothelial cells. J Cell Biol 107:321-331.

Edgell CJ, McDonald CC, and Graham JB (1983). Permanent cell line expressing human factor VIII-related antigen established by hybridization. Proc Natl Acad Sci USA 80:37343737.

Farwell D, Shera K, Koop J, Bonner G, Matthews C, Reuther G, Coltrera M, McDoughall J, and Klingelhutz A (2000). Genetic and epigenetic changes in human epithelial cells immortalized by telomerase. Am J Pathol 156:1537-1547.

Fickling S, Tooze J, and Whitley G (1992). Characterization of human umbilical vein endothelial cell lines produced by transfection with the early region of SV40. Exp Cell Res 201:517-521.

Fogh J and Trempe G (1975). Human tumor cells in vitro. New York: Plenum Publishing Corporation, 115-141.

Fontijn R, Hop C, Brinkman H, Slater R, Westerveld A, van Mourik J, and Pannekoek H (1995). Maintenance of vascular endothelial cell-specific properties after immortalization with an amphotropic replication-deficient retrovirus containing human papilloma virus 16 E6/E7 DNA. Exp Cell Res 216:199207

Gimbrone M and Fareed G (1976). Transformation of cultured human vascular endothelium by SV40 DNA. Cell 9:685-693.

Goldfarb M, Shimizu K, Perucho M, and Wigler M (1982). Isolation and preliminary characterization of a human transforming gene from T24 bladder carcinoma cells. Nature 296:404-409.

Halvorsen T, Leibowitz G, and Levine F (1999). Telomerase activity is sufficient to allow transformed cells to escape from crisis. Mol Cell Biol 19:1864-1870.

Hewett P and Murray J (1993). Human microvessel endothelial cells: Isolation, culture, and characterization. In Vitro Cell Dev Biol Anim 29A:823-830.

Hohenwarter O, Jakoubek A, Schmatz $\mathrm{C}$, and Katinger $\mathrm{H}$ (1994). Expression of SV40 tumour antigens enables human endothelial cells to grow independently from fetal calf serum and exogenous growth factors. J Biotechnol 15:205-211.

Hoover ML, Vetvicka V, Hoffpauir JM, and Tamburro CH (1993). Human endothelial cell line from an angiosarcoma [letter]. In Vitro Cell Dev Biol 29A:199-202.

Jaffe E, Nachman R, Becker C, and Minick C (1973). Culture of human endothelial cells derived from umbilical veins. Identification by morphologic and immunologic criteria. J Clin Invest 52:2745-2756.
Jiang $X$, Jimenez G, Chang E, Frolkis M, Kusler B, Sage M, Beeche M, Bodnar A, Wahl G, Tlsty T, and Chiu C (1999). Telomerase expression in human somatic cells does not induce changes associated with transformed phenotype. Nat Genet 21:111-114.

Kirkpatrick CJ, Bittinger F, Klein C, Hauptmann S, and Klosterhalfen B (1996). The role of the microcirculation in multiple organ dysfunction syndrome (MODS): A review and perspective. Virchows Arch 427:461-476.

Kiyono T, Foster SA, Koop JI, McDougall JK, Galloway DA, and Klingelhutz AJ (1998). Both Rb/p16INK4a inactivation and telomerase activity are required to immortalize human epithelial cells. Nature 396:84-88.

Lawley T and Kubota Y (1989). Induction of morphologic differentiation of endothelial cells in culture. J Invest Dermatol 93:59S-61S

Lehr H, Bittinger F, and Kirkpatrick CJ (2000). Microcirculatory dysfunction in sepsis: A pathogenetic basis for therapy? J Pathol 190:373-386.

MacKenzie K, Franco S, May C, Sadelain M, and Moore M (2000). Mass cultured human fibroblasts overexpressing hTERT encounter a growth crisis following an extended period of proliferation. Exp Cell Res 259:336-350.

Masuzawa M, Fujimura T, Hamada $Y$, Fujita $Y$, Hara $H$, Nishiyama S, Katsuoka K, Tamauchi H, and Sakurai Y (1999). Establishment of a human hemangiosarcoma cell line (ISOHAS). Int J Cancer 81:305-308.

Migliaccio M, Amacker M, Just T, Reichenbach P, Valmori D, Cerottini J-C, Romero P, and Nabholz M (2000). Ectopic human telomerase catalytic subunit expression maintains telomere length but is not sufficient for CD8 + T lymphocyte immortalization. J Immunol 165:4978-4984.

Olovnikov A (1973). A theory of marginotomy: The incomplete copying of template margin in enzymatic synthesis of polynucleotides and the biological significance of the phenomenon. J Theor Biol 41:181-190.

Osborn L, Hession C, Tizard R, Vassallo C, Luhowskyj S, Chi-Rosso G, and Lobb R (1989). Direct Expression cloning of vascular celladhesion molecule 1 , a cytokine-induced endothelial protein that binds to lymphocytes. Cell 59:12031211.

Reznikoff C and DeMars R (1981). In vitro chemical mutagenesis and viral transformation of human endothelial cell strain. Cancer Res 41:1114-1126.

Sabapathy K, Pepper M, Kiefer F, Mohle-Steinlein U, Tacchini-Cottier F, Fetka I, Breier G, Rissau W, Carmeliet P, Montesano R, and Wagner E (1997). Polyoma middle T-induced vascular tumor formation: The role of the plasminogen activator/plasmin system. J Cell Biol 137:953-963.

Southern P and Berg P (1982). Transformation of mammalian cells to antibiotic resistance with a bacterial gene under control of the SV40 early region promoter. J Mol Appl Genet $1: 327-341$

Stanton L, Watt R, and Marcu K (1983). Translocation, breakage and truncated transcripts of c-myc oncogene inmurine plasmacytomas. Nature 303:401-406.

Takahashi K, Sawasaki Y, Hata J-I, Mukai K, and Goto T (1990). Spontaneous transformation and immortalization of human endothelial cells. In Vitro Cell Dev Biol 25:265-274. 
van Leeuwen E, Veenstra R, van Wijk R, Molema G, Hoekstra A, Ruiters M, and van der Meer, J (2000). Characterization of immortalized human umbilcal and ilial vein endothelial cell lines after transfecton with SV40 large T-antigen. Blood Coagul Fibrinolysis 11:15-25.

Wautier M, Chappey O, Vicart P, Paulin D, and Wautier J (1999). Immortalized human endothelial cells have a decreased response to an IL-1 receptor defective expression restored by corticosteroids. Cell Biol Toxicol 15:153-161.
Yang J, Chang E, Cherry AM, Bangs CD, Oei Y, Bodnar A, Bronstein A, Chiu CP, and Herron GS (1999). Human endothelial cell life extension by telomerase expression. J Biol Chem 274:26141-26148.

Zhu J, Wang H, Bishop JM, and Blackburn EH (1999). Telomerase extends the lifespan of virus-transformed human cells without net telomere lengthening. Proc Natl Acad Sci USA 96:3723-3728. 